\title{
LA FORMULACIÓN DE UNA DEFINICIÓN DEL ESCEPTICISMO POLÍTICO
}

\author{
Silvia Molina y Vedia
}

Una observación sistemática no se alcanza por medio del simple acto de observar. Una observación sistemática significa observar "algo" siguiendo una determinada teoría y su método, con un propósito u objetivo de conocimiento. Es observar un objeto del mundo ' que por un acto de voluntad se convierte temporalmente en "objeto" de estudio.

Tanto para comunicar posteriormente nuestras observaciones como para extraer consecuencias de ellas, ese "objeto" se tiene que destacar especialmente del resto del mundo. Para ello se fijan ciertos parámetros apropiados para su caracterización, es decir, se lo define ${ }^{2}$.

Dentro de esta perspectiva una definición no puede ser meramente ostensiva ni tampoco tautológica. Una definición se construye con elementos derivados de la teoríamétodo, que sin embargo no son ajenos al objeto que se define, sino rasgos distintivos del objeto mismo, percibidos desde el encuadre teórico.

\footnotetext{
I Siguiendo la perspectiva de N. Luhmann, se considera al mundo como el horizonte último de sentido, simultánemente autocontenido y trascendente.

${ }^{2}$ Una definición es la restricción de posibilidad de otras definiciones.
} 
Cualquier objeto de estudio puede concebirse, en principio, de formas muy diversas. El sentido ${ }^{3}$ de la definición estará dado por la teoría.

Partiendo de estos antecedentes generales escuetamente expresados, el objetivo de este trabajo consiste en formular una definición de escepticismo político (que tome en cuenta sus componentes objetivos y subjetivos), construida a partir de la teoría de $\mathrm{N}$. Luhmann sobre los sistemas sociales. Esta definición no debe admitir más que una sola interpretación, desde la cual será capaz de transformarse o evolucionar ${ }^{4} \sin$ dejar de ser lo que es ni de designar lo que designa (la forma en que esto sucede se explica mediante el fonómeno de la autorreferencia ${ }^{5}$ ).

La teoría de los sistemas sociales de N. Luhmann, tanto por su proceso operativo como por algunos de los conceptos centrales que maneja (autorreferencia, sentido, comunicación ${ }^{6}$ ) permite construir una definición de escepticismo político partiendo desde el código binario hasta lograr el objetivo de definir el escepticismo político teórica, lógica y operacionalmente.

Luhmann señala que en la base de un código existe siempre una unidad bipolar que se transforma y evoluciona hacia la complejidad mediante un proceso autorreferente.

\footnotetext{
${ }^{3}$ En la perspectiva de N. Luhmann, el sentido se refiere a la forma y no al contenido; es una forma de reproducción que permite el asimiento puntual en donde queda colocada y que al mismo tiempo, permite identificar cualquier asimiento como selección.

"La evolución está entendida aquí como incremento de la complejidad, como evolución de lo más simple a lo más complejo.

${ }^{5} \mathrm{La}$ autorreferencia es el proceso que consiste de elementos o acontecimientos que al retomar su relación con otros elementos del mismo proceso se remiten a sí mismos. Al partir de una unidad compleja, la autorreferencia elimina la tautología por asimetrización.

${ }^{6}$ Comunicación se entiende aquí como selectividad en la información, la notificación y la expectativa de éxito. Es el ultraelemento de los sistemas sociales. Consiste en un proceso autorreferencial en el cual se desarrolla la selectividad entre alter y ego. La operación autorreferencial se realiza a partir de un código. El código es un esquema general, estructurado sobre un cje dual y asimétrico, que permite ordenar la contingencia (generada por la incesante autorreferencia) y posibilitar la comunicación, a cuyo fin se encuentra ordenado.
}

Rua, Campinas, 2:117-139, 1996 
El criterio básico mediante el cual opera esta autorreferencia consiste en la observación-diferenciación. Siguiendo esta lógica es posible construir una formación derivada del código binario apta para definir el escepticismo político bajo las condiciones señaladas en nuestro objetivo.

Éste es el punto de partida: $0-1$

Partiendo de esta unidad, que ya es en sí una unidad de la diferencia, se pueden realizar diversas operaciones de agrupamiento simple, que remiten siempre en última instancia a la fórmula inicial 0-1 (a pesar de que en algún momento parecen alejarse de él); al observar y diferenciar estas operaciones es posible reconocer, diferenciar y nombrar algunas de ellas. En eso consisten las primeras observaciones que se hacen, y de acuerdo con las cuales se construyó el primer concepto complejo con el que se trabajará: el de duda.

\section{0}

11111111

01001011111

01010101

Estas son disposiciones en serie basadas en el código utilizado.

Al observar las series anteriores se pueden distinguir unas que están compuestas del mismo término y que por lo tanto se designan como series congruentes, y otras en las que aparecen ambos términos que se designan series incongruentes.

En todas las series congruentes, y en algunos casos las series incongruentes, es posible anticipar cuál será el término que aparecerá a continuación. Cuando es posible predecir este término con cierta seguridad se afirma que la serie es probabilística.

$11111111111111 \ldots \quad$ Serie congruente y probabilística. 
$01010101010101 \ldots$

$01011011101111 \ldots \quad$ Series incongruentes y probabilísticas.

$01001000100001 \ldots$

Pero si la serie, además de ser incongruente, no manifiesta ningún ritmo o progresión, entonces se trata de una serie cuyos elementos se ordenan por azar.

Serie al azar

001111111111011000001000011111010100000

Por otro lado, una serie puede ser o estar completa o incompleta según se expresen o no todos sus términos posibles. En una perspectiva pragmática, tomando en cuenta las limitaciones humanas para la manipulación de datos, el caso extremo de la incompletitud es el infinito (que se presupone pero nunca se alcanza).

Las series probabilísticas suelen serlo en función de un ritmo o frecuencia que se manifiesta en la aparición de sus términos. Pero existen casos en que este ritmo tiene cienta particularidad; contrapone los términos de la siguiente manera

\section{0}

Cuando se producen figuras como la anterior, o equivalentes en su disposición a ella, diremos que esa serie es contradictoria.

Asimismo, cada uno de los términos que puede o no aparecer en la sucesión de una serie incongruente constituida al azar es improbable hasta el momento mismo en que aparece (se hace presente).

Una serie también puede fragmentarse. Las series fragmentadas y los fragmentos de una serie constituyen formas diversas en sí mismas, que guardan relación con los tipos de series a los que ya se hizo referencia. En realidad existen muchos casos en los que se desconoce si la serie está completa o no y también si va a fragmentarse o no. Esto proporciona nuevos espacios a perspectiva de la probabilidad-improbabilidad.

Finalmente, podemos hablar de que existen series contingentes desde el momento mismo en que constatamos mediante observación que las series que se van construyendo 
pueden cambiar en el proceso, dejar de ser congruentes o de ser probables, o al revés, hacerse probables y superar el azar.

Las series congruentes o incongruentes, probabilísticas o improbables (al azar), completas o incompletas, contradictorias o no, y también las contingentes, son todas y cada una de ellas portadoras de sentido. Parafraseando a N. Luhmann, el sentido es el proceso de dar forma - en nuestros ejemplos - a cada serie. El sentido se va adquiriendo en el proceso de configuración de la serie (o del conjunto, o del grupo, etc.) y es lo que permite establecer la diferenciación entre - continuando con el ejemplo - una serie y lo demás (su entorno). Además, a través del sentido se puede invertir la serie, convertirla en contradictoria, o trasformarla.

A partir de lo expuesto, cuando se presentan combinaciones de series
incongruentes, contradictorias, incompletas, improbables y
contingentes, se genera un tipo de sentido que indica que existe duda.

La duda es, entonces, una situación en la cual existe incertidumbre frente a cómo se desarrolla el sentido de una serie (o como lo veremos más adelante, un conjunto). Tanto si operamos con el código 0-1 o con cualquier otro, la duda induce sentido, o bien hacia la superación de la duda y la búsqueda de estabilidad (entendida como reencuentro con la probabilidad) procurando reducir la improbabilidad, completando to inacabado, pretendiendo eliminar la contingencia, o bien propulsando en su operación un motor de sentido autorreferente (que se tratará más adelante).

¿Pero cómo es posible definir ahora el concepto de escepticismo utilizando la definición de duda a la que se arribó, y sin abandonar el código binario que fue el punto de partida?

En principio, es necesario volver al código 0-1 y retomarlo en otra perspectiva. Así, puedo encontrar la siguiente distribución: 


$\begin{array}{lllll}1 & & 0 & 0 & 11 \\ 0 & 1 & 0000 & 111111 \\ 0 & 0 & 1 & 0 & 00\end{array}$

y también puedo agruparla de acuerdo con algún criterio distinto de los que se utilizaron para configurar las series; por ejemplo:

$\begin{array}{rl}111 & 00 \\ 111111 & 00000 \\ 1 & 00000\end{array}$

En el primer caso, se presentó un conjunto desordenado y en el segundo, un conjunto ordenado. El orden provino de una decisión, no del azar. Esta decisión de reunir los términos iguales en sectores diferentes permite construir la noción más elemental de grupo.

No obstante es posible también configurar grupos heterogénos cuando los términos que se separan del conjunto inicial reunen ambos términos indistintamente, tal como se muestra a continuación:

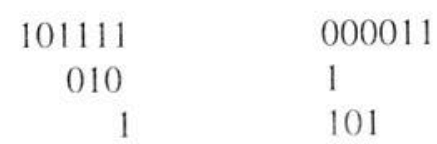

Si observo el siguiente conjunto:

$\begin{array}{rrl} & 111 & 0000 \\ 1 \quad 1 & 0 \\ & 1 & 0000\end{array}$


descubro que el criterio para la formación de cada grupo fue la concentración de términos similares. El mismo criterio se puede aplicar en la construcción de series, tal como se muestra en el ejemplo que sigue:

\section{0}

Cuando al comparar conjuntos, o conjuntos y series, se observa la aplicación de un mismo criterio de distribución de los términos, éstos (conjuntos/series) son considerados semejantes; si no se observa, son diferentes. La semejanza es un tipo de manifestación de sentido.

En consecuencia, los conjuntos, los grupos y las series pueden guardar entre si semejanza o diferencia respecto de los criterios a partir de los cuales fueron construidos o son observados.

Cuando se encuentran semejanzas entre diversos conjuntos, grupos o series, se puede decir que todos ellos están asociados (vinculados) entre sí.

Además, en el interior de un mismo conjunto, los términos pueden encontrarse vinculados de alguna manera: por orden de aparición, por contigüidad física, etc. No todos los términos de un conjunto tienen que estar vinculados entre sí de la misma manera, y algunos pueden no estarlo en absoluto. De esta manera, el conjunto en cuestión puede tomar la forma siguiente (u otra similar):

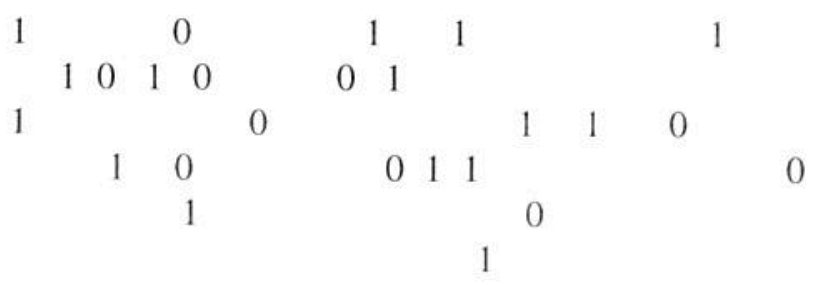

Al observar este conjunto se constata que difiere por sus relaciones, y por la direccionalidad de éstas, de los otros conjuntos que se presentaron con anterioridad. Este 
conjunto especial se llama red. La direccionalidad de los vínculos entre los elementos constitutivos en las redes significan:

Relación: que es la vinculación que enlaza dos términos entre sí.

Aislamiento: que es la situación en que quedan los términos del conjunto que carecen por completo de relaciones.

Comunicación: que es la relación en términos de selección. ${ }^{7}$

Por otro lado, la construcción de series o conjuntos puede ser deliberada o no deliberada. Cuando es deliberada o intencional, existe un propósito o meta que orienta la construcción. A éste se lo define como objetivo o meta.

Al llegar a este punto es posible desarrollar diversos conceptos sobre la base de la combinación de las operaciones elaboradas hasta ahora. De esta manera,

a la combinación de:

podemos llamarla:

\begin{tabular}{ll}
\hline Red - comunicación - azar - objetivo & Juego \\
Red - comunicación - ordenamiento & Organización \\
Red - comunicación - duda & Escepticismo
\end{tabular}

Pero la definición de escepticismo a la que se arriba no resulta totalmente satisfactoria porque no es producto más que de relaciones objetivas, y al principio de este trabajo se indicó que el escepticismo también tenía componentes subjetivos. En consecuencia, partiendo del mismo código binario hay que desarrollar una forma de incluir la subjetividad en el concepto de escepticismo.

\footnotetext{
${ }^{7}$ Coincidiendo una vez más con la teoría de los sistemas sociales de N. Luhmann, se aclara que la comunicación es selectividad; y esta última se manifesta en tres aspectos, a saber, selección de la información (en el caso que nos ocupa, selección entre 0 y 1), selección de la notificación (en el caso en que nos ocupa, selección de cómo se va a estructurar la serie o el conjunto, es decir, con qué términos 0-1 y en qué orden) y selección del destinatario (en el caso que nos ocupa, a qué 0 o 1 de la red se dirige la comunicación).
}

Rua, Campinas, 2:117-139, 1996 
La única forma sencilla de tratar la subjetividad a partir de la objetividad del código binario surge en el momento en que este se "traduce" a la numeración decimal (que tiene en su base al código binario).

De este modo, por ejemplo:

\section{1 puedo representarlo como 4}

1111 puede tener una existencia (presencia) objetiva, 4 en cambio, es un símbolo. La traducción realizada no resulta forzada porque en la historia misma sucede igual; se pasa de 1111 a 4, y con la posibilidad de pensar numéricamente algunas de las operaciones más laboriosas dentro del juego del código binario pueden resolverse de manera abreviada.

Este pasaje del código binario al sistema numérico decimal produce también una trasformación cualitativa de la conceptualización. Se conceptualiza ahora según símbolos (números) que significam algún estado de la relación binaria.

Desde el momento en que existe el símbolo, también existe la abstracción que tiene la doble función de reducir la complejidad y de incrementar las operaciones generalizadoras (operaciones con símbolos).

Por medio de una operación generalizadora que reconoce un espacio propio a las abstracciones simbólicas y origen común (binario) a los términos en que se expresan, se puede decir que:

La relación, selección, ordenamiento, direccionalidad y probabilidad de sentido de los conjuntos simbólicos (y los juegos y/o constrastes resultantes de su operación) se denominan subjetividad.

La subjetividad, dentro de este planteamiento, admite en su origen la existencia de información objetiva que ha sido configurada con símbolos mediante un procedimiento de traducción. 
Esto significa que en el origen mismo de estos símbolos se encuentran datos obtenidos a través de la operación del código original 0-1. Sin embargo, las operaciones subjetivas a las que hasta ahora se ha hecho referencia, permitem a su vez deducir símbolos de otros símbolos o construir símbolos de segundo grado, los cuales también pueden relacionarse de múltiples formas.

Lo anterior nos conduce a la conclusión, consecuente con las previsiones de Luhmann, de una evolución acéntrica y multidireccional hacia la complejidad. Es decir, que en términos de la subjetividad se puede constatar una evolución que opera con datos primitivamente objetivos y que tiende a diversificar su producción de una forma que podría parecer caótica.

No obstante, la multiplicación simbólica no se realiza al margen del sentido. Sentido que está dado por los universos de posibilidad que se abren a partir de la primera selección (o combinación del código), al mismo tiempo que se eliminan los que quedan al margen de la selección inicial, y que en cada nueva selección se van abriendo - y simultáneamente cerrando - a nuevos espacios de posibilidad.

De esta forma, la selección incrementa y reduce la complejidad.

La incrementa porque ofrece oportunidades de ampliar las posibilidades operativas del código. La reduce, porque no admite o ignora aquello que se encuentra más allá del límite de la selección dada.

El procesamiento sistemático de dudas que se realiza mediante una selección continua cuyo origen es objetivo originado en el código binario puede también en su conjunto o en parte, combinarse con procesos simbólicos equiparables o semejantes al primero.

Atendiendo a este posible doble aspecto objetivo-subjetivo de la duda, se la puede interpretar como una forma de reducir lo que se percibe como confusión, incertidumbre, ambigüedad y que se conjuga en última instancia en torno a la improbabilidad, reformulándolo en forma interrogativa (preguntas) para poderlo manejar y utilizarlo en la búsqueda de mayor información o relegarlo por estéril. En otras palabras, la duda es una forma de reducir la confusión por selección, que impone de inmediato sentido a la duda misma y, seguidamente, a las secuencias (contingencias) que podrían derivarse de ella. 
Series y conjuntos simbólicos incongruentes, improbables, contingentes, incompletos o fragmentarios, es decir, los diversos elementos que dan lugar a la duda, cuando son autorreferencialmente procesados (es decir, cuando son procesados desde el código mismo que implanta la duda), constituyen una situación o fenómeno nuevo. Este nuevo fenómeno va mucho más allá de la duda como originalmente se la definió y nos remite directamente al escepticismo.

Se denomina escepticismo al procesamiento de la duda, tanto en su proyección objetiva como en su dimensión subjetiva

En su generalidad, entonces, el escepticismo es una forma de procesamiento autorreferencial de la duda que puede expresarse, atendiendo a la teoría de Luhmann sobre los sistemas sociales, a dos niveles autónomos: el de la sociedad, donde se manifiesta mediante la comunicación, y el del individuo o sistema psíquico, donde se manifiesta a nivel del pensamiento ${ }^{8}$.

En consecuencia, existen dos formas generales y diferentes de escepticismo: el que se produce y comunica en ciertos sectores del sistema social y el que algunos individuos elaboran, cada uno de ellos en su propia conciencia a través del proceso de pensamiento. Cada una de estas formas de escepticismo, al desarrollarse en niveles sistémicamente incompatibles de acuerdo con la teoría de Luhmann, tiene que ser abordada con propósitos de investigación, con recursos diferentes.

Sin embargo, el escepticismo tanto a nivel social como de cada individuo puede estar referido a objetos similares. Con ello, su dimensión formal se dota a sí misma de contenido.

\footnotetext{
8 Mayores detalles sobre las formas de operación de los sistemas sociales y psíquicos se encuentran en Sistemas sociales, obra de Niklas Luhmann publicada por Alianza Editorial, México, 1991. Con propósitos de aclarar las diferencias que median en esta teoría entre los sistemas psíquicos y los sociales, también puede consultarse "Individuo y sociedad: el desencuentro" de Silvia Molina y Vedia, publicación interna del Centro de Estudios de la Comunicación de la FCPS de la UNAM, México, 1991.
} 
El siguiente problema, que se plantea de acuerdo con el objetivo de definir lo que es el escepticismo político, consiste en demonstrar la relación que se estabelece desde el escepticismo cuando éste procesa contenidos significativos propios del subsistema político.

Antes de entrar directamente en esta cuestión es necesario aclarar una serie de conceptos que facilitan la comprensión de las características del subsistema político.

En primer término, hay que aclarar qué es un sistema y cómo se forman subsistemas en su interior.

Para ello es posible retomar la definición de red que se presentó anteriormente. La red que se empleó en el ejemplo correspondiente refleja una distribución de los términos (en ese caso binarios) de un conjunto y sus vinculaciones. Esa red, sin embargo, se supone relativamente estática porque aunque las relaciones pueden estar indicando intercambios entre los términos, estas relaciones se definen siempre entre los mismos términos. Esa red se entiende entonces como una estuctura estática.

Es posible jugar con los términos de una red de modo que estos varíen y se encuentren sujetos a todo tipo de contingencias, utilizando como criterio para la variación la generación autopoyética y autorreferencial. La imagen estática de la red con su estructura de relaciones se rompe para dar lugar, así, a nuevos juegos de sentido. La formación cambiante que surge entoces se llama sistema. Los sistemas tienen la particularidad de que no son simples construcciones teóricas, sino que opera como tales en la realidad; es decir, que tienen también existencia objetiva a través de diversos tipos de "soportes". Estos soportes pueden ser circuitos en una computadora, comunicaciones en una sociedad o la conciencia de un individuo.

El cambio autorreferencial de un sistema genera por autopoyesis una evolución creciente hacia la complejidad, que el propio sistema no podría tolerar si como es el caso de los sistemas vivos, del sistema social y de los sistemas inteligentes no creara sus propios mecanismos para reducir esta complejidad.

Una forma de reducir la complejidad del sistema es la formación de subsistemas, mediante la cual el sistema incrementa la eficiencia y restringe las posibilidades de improcesabilidad de la información que maneja y genera constantemente. Esta especial "división del trabajo" sitúa a los subsistemas como elaboradores y procesadores de 
sentidos muy especializados que operan su propio proceso autorreferencial en forma relativamente independiente unos de otros con base en el manejo de su propio código. En otras palabras, un sistema genera subsistemas por diferenciación, mediante el establecimiento de límites internos. Cada subsistema repite en su interior aspectos del sistema al cual pertenece.

El subsistema político es uno de los subsistemas en los que se organiza el sentido en las sociedades más desarrolladas. Luhmann señala que el código propio del sistema político, mediante el cual opera la comunicación, gira en torno a dos instancias fundamentales: el gobierno y la oposición. Lo que parece notable es que el escepticismo, como forma de comunicación autorreferente de la duda, es capaz de situarse sobre este código como un hipercódigo capaz, al transformar en duda el discurso del gobierno y la oposición, de sustraerlo de su especificidad como subsistema y proyectar un escepticismo que elabora su juego de sentido con términos propios de la política. De esta manera:

La imposición del código de la probabilidad-improbabilidad, que hace prevalecer la duda como forma emergente de sentido sobre el código del gobierno y la oposición, se denomina escepticismo político.

Sin embargo, esta definición no adelanta nada acerca de los procesos que desencadena el escepticismo político. En realidad éstos escaparían en principio a la pretensión de formular un concepto. A pesar de lo cual no es totalmente así. No, si se ha construido la definición desde un soporte teórico como el que Luhmann proporciona en su teoría de los sistemas sociales autorreferentes y autopoiéticos.

De esta definición se deducen también otras observaciones, por ejemplo:

a) que el escepticismo es una de las formas generales de sentido que orientan la comunicación, imponiendo la duda como criterio rector en el código probabilidadimprobabilidad y a través del mismo, convirtiendo en duda todo significado;

b) que este tipo de procesamiento de la comunicación (sentido) al operar afecta seriemente los espacios (subsistemas) de los que extrae los significados con que su sentido opera; 
c) que la necesidad funcional de todo sistema de controlar su propio código para incrementar su diferenciación sistémica genera "respuestas" sumamente variadas que tratan de nulificar los efectos devastadores del escepticismo, dentro de variantes de sentido que oscilan entre el funcionalismo ${ }^{9}$ y la renovación, y

d) que el escepticismo, mediante su propia "negatividad", es capaz de abrir espacios de sentido cada vez más complejos y elaborados, que dejan tras de sí una vasta estela de significados contingentes, proceso simultáneo y policéntricamente expandido a las opciones que clausuran o expanden su propia posibilidad.

Resulta de esta manera que nuestra definición se abre a sí misma un campo de sentido que requiere ser explorado con mayor profundidad. De modo tal que su formulación posibilita de inmediato una apertura dinámica y mutable: ofrece un horizonte de sentido.

\footnotetext{
${ }^{9}$ El funcionalismo es entendido en este párrafo como "funcionamiento", en el contexto se alude a la búsqueda de alternativas para restabelecer la funcionalidad, el funcionamento propio del sistema o subsistema.
} 


\section{BOSQUEJO DE UN MODELO DE LA FORMA EN QUE OPERA EL ESCEPTICISMO DENTRO DEL SUBSISTEMA POLÍTICO ${ }^{10}$}

El escepticismo es un hipercódigo de la comunicación que opera autorreferencialmente, es decir, que processa incessantemente la duda dentro de los parámetros fijados por el código de la improbabilidad-probabilidad.

Decimos que es un hipercódigo, porque tiene la capacidad de imponer su sentido sobre otros códigos. Mediante esta capacidad para imponer sentido a otros, logra afectar sentidos y significados de diversos subsistemas, incrementando su propia apertura al sentido. ${ }^{11}$

Hablamos de escepticismo político cuando el escepticismo se sitúa a nivel del subsistema político provocando alteraciones en él. Al ocurrir esto se empieza a dudar de todo lo que dice, hace, no dice, no hace, y de lo que podrían decir y hacer, el gobierno y la oposición, y son cuestionadas también las reglas que norman la acción y comunicación política, así como sus instituciones. Todo lo que constituye el subsistema político puede ser puesto en duda, inclusive la utilidad o conveniencia de que este subsistema exista.

Vamos a trazar un bosquejo de modelo que trata de aclarar las siguientes cuestiones: ¿Qué permite operar el código del escepticismo en el campo político? ¿Cómo repercute el escepticismo político en el interior del correspondiente subsistema? y ¿Cuándo es posible abandonar el código del escepticismo político?

\footnotetext{
${ }^{10} \mathrm{El}$ proyecto de investigación "Escepticismo Político y Comunicación de Masas" se realiza con el apoyo financiero del "Programa de Apoyo a la Investigación e Innovación Docente" de la DGAPA, Universidad Nacional Autónoma de México.

${ }^{11}$ El sentido, dentro de la teoría de Luhmann, lo es según la forma y no el contenido. Es reproducción de la complejidad misma que permite el asimiento puntual ahí donde queda colocada, pero que a la vez identifica todo posible asimiento como selección. Cada intención de sentido es autorreferencial desde el momento en que prevé su propia posibilidad de reactualización. El sentido no permite más que la selección.
}

Rua, Campinas, 2:117-139, 1996 
1. ¿Qué permite operar el código del escepticismo en el subsistema político?

En términos generales lo que permite operar el código del escepticismo en el subsistema político es la proliferación de comunicaciones en su interior y la incapacidad para reducirlas y aprovecharlas en su desarrollo (figuradamente podríamos decir que el escepticismo político se genera por sobrealimentación del sistema o exceso de comunicación).

El proceso por el cual esto ocurre no es tan sencillo de explicar. A continuación se esbozarán en grandes trazos los aspectos más relevantes de este proceso.

Como antecedente, tenemos que aclarar que los subsistemas se generan debido a la necesidad del sistema social de reducir la proliferación de comunicación en su interior, y al mismo tiempo, de producir una comunicación selectivamente útil para el propio sistema. Cada subsistema desarrolla un tipo de comunicación que le es propia, a partir del manejo autorreferencial de un código específico. Así, por ejemplo, el código de la política es el del gobierno y la oposición y, en consecuencia, cualquier comunicación que se diga política tendrá que estar referida a este código (por ejemplo: las crísticas a las realizaciones del gobierno, las campañas para promover reformas electorales, los discursos de los candidatos y funcionarios de gobierno, los comentarios familiares acerca de la oportunidad o no con que el presidente hizo declaraciones en público, etc.).

De esta manera, el subsistema político existe con base en la propia comunicación que genera, del mismo modo en que lo hacen otros subsistemas.

Además, en las sociedades actuales, se ha desarrollado un subsistema que afecta a todos los otros, debido al tipo de código que opera y las consecuencias que puede provocar. Se trata del subsistema que integra el complejo de los medios de difusión masiva, cuyo código implica la selección: es noticia, no es noticia. La noticia lo es una sola vez, pero puede tratar cualquier cosa, ya que no existen restricciones para lo que es noticia. En consecuencia, el complejo de los medios masivos de difusión emite comunicaciones en todas direcciones dentro del sistema social, muchas de las cuales afectan al subsistema político (porque se refieren al código del gobierno y la oposición) y las restantes a otros subsistemas. 
Tenemos así un subsistema político que genera y maneja su propia comunicación y que se apropia (por interprenetración) de la comunicación que - principalmente - es capaz de captar de la que los medios de difusión masiva producen (y hacia los cuales también deja filtrar comunicación que los medios transforman inmediatamente en noticias).

Mientras el subsistema político dispone de recursos para eliminar la complejidad que recibe desde los medios de difusión masiva, aparte de la que él mismo genera, la comunicación se va encauzando dentro de instituciones, programas políticos, proyectos concretos, juegos políticos, etc., donde operan sus propios criterios selectivos.

No obstante, lo que permite operar al escepticismo político se debe a que pueden quedar residuos que no sean absorbidos por el subsistema.

En general, estos "residuos" deberían ser reducidos o anulados para no afectar la operación del subsistema. Los mecanismos que se utilizan para tal efecto son: la posposición sistemática de ciertos problemas (se los difiere en el tiempo, y con ello se "gana" tiempo para resolverlos eventualmente), la represión (como supresión violenta) y el silenciamento (o apagamiento del problema, según el cual el problema no desaparece ni se soluciona ni se lo reprime, sino que se deja de hablar de él, se sustituye su espacio de comunicación con otras comunicaciones ${ }^{12}$ como si no existiera).

Si de todas maneras la comunicación prolifera rebasando todo mecanismo para su reducción (lo que frecuentemente ocurre en pequeña escala sin afectar notablemente al subsistema), y traspasa algunos niveles de tolerancia, el sentido empieza a proliferar de manera incontrolable en ciertos sectores (si ocurriera a nivel de todo el subsistema acabaría con él, pero la complejdad del subsistema político es tal, que dispone de muchas formas en muchos niveles para que le permiten operar y reducir selectivamente la complejidad).

Además, la acción del complejo de medios de difusión masiva afecta a todo el sistema social, no sólo por las noticias y el consecuente sentido abierto a la comunicación, sino que por medio del mismo, también obliga a los sistemas a generar

\footnotetext{
${ }^{12} \mathrm{Al}$ respecto se recomienda la lectura de la obra de Eni Pulcinelli Orlandi, As formas do silêncio, publicado por la Universidad de Campinas, São Paulo, Brasil, 1991.
}

Rua, Campinas, 2:117-139, 1996 
tópicos para reducirla (selecciones de sentido ${ }^{13}$ ). Es decir, que provoca un proceso de interpenetración mediante el cual otros subsistemas tienen que manejar la autorrefencia de modo que les permita apropiarse o reconocer algo que está en su entorno y les interesa.

Pero la comunicación (tanto la originada dentro como la que el subsistema se apropia de su entorno), que es selección de sentido, no implica necesariamernte que lo sea de un sólo sentido; desde que se formula queda abierta a un mundo de sentido.

Tanto la comunicación que produce el propio subsistema político, como la que es capaz de apropiarse por medio de la interpenetración, poseen esta capacidad de apertura de sentido (que tiende a ser reducida y que en parte escapa a la reducción).

Una parte de la comunicación que no alcanza a ser reducida en su complejidad, pasa a ser "ruido", o sea, a formar parte de una amalgama confusa que demora o distrae la operación del subsistema. Otra parte de la comunicación que no alcanza a ser reducida en su complejidad, y fragmentos de "ruido", puede procesarse y también vincularse, alcanzando una forma especial de sentido que es la duda

La duda en sí es una manera de reducir la complejidad de la comunicación posponiendo cualquier tipo de decisión. Al mismo tiempo está abierta al sentido de dos formas que nos interesan particularmente: a) la búsqueda de un sentido compatible con la comunicación que se genera en el subsistema y b) el procesamiento autorreferencial que convierte a la duda en dudas de distinta naturaleza (lo que llamamos escepticismo político) $)^{14}$.

El escepticismo político se desarrolla al mismo tiempo que la búsqueda de sentido dentro del subsistema. Ambas formas de duda comienzan a actuar en el sistema, una de ellas reelaborará todo lo que encuentre como duda, la otra procurará encontrar algún objeto, creencia, convención, institución o campo (donde observe posibilidades de certeza), sobre el cual invertir su sentido.

Ambas a su vez pueden transformarse (una en la otra).

\footnotetext{
${ }^{13}$ Fenómeno éste interpretado en otro contexto como teoría de la agenda setting.

${ }^{14}$ La pérdida de la identidad se reconoce en la falta de control sobre su propio código y, en consecuencia, su incapacidad para conocer y tijar sus propios límites.
} 
El escepticismo político que opera al nivel de los mecanismos (no de las unidades) del sistema; en su proceso a) hace incompetentes ciertos ámbitos operativos del subsistema y b) se reelabora a sí mismo al margen del control y con creciente autonomía. De esta manera genera un proceso que comienza a afectar seriamente la identidad del subsistema (éstas son las razones por las cuales, y a través de la historia, el escepticismo ha sido satanizado y combatido con saña). Cuando la identidad (entendida como integridad) del subsistema político está afectada por el escepticismo, decimos que existe escepticismo político.

2. ¿Cómo opera el escepticismo político en el interior del correspondiente subsistema?

En general, podemos decir que el escepticismo político crea dentro del sistema político conmociones internas importantes y que, antes de desaparecer, lo obliga a realizar cambios, cuya profundidad dependerá directamente de la forma en que el sistema se haya visto afectado, el "precio" que esté dispuesto a pagar para su recuperación, y si el daño total que se le haya causado no afectó irreversiblemente algunas de sus partes.

El proceso que resumimos es muy complejo. En primer término, porque la duda no necesariamente aflora en un punto específico del sistema, y a medida que se llega a procesar autorreferentemente se manifiesta desde una pluralidad de centros (como si fuera un barco que hace agua por muchos lados sin que se sepa bien cuál hoyo hay que taponit primero). En segundo término, porque el subsistema tarda (unos más y otros menos) en detectarla y en calificarla como un problema importante, ya que al principio suele desecharla como simple "ruido".

Por otro lado no todo el subsistema político se ve afectado de la misma forma por el escepticismo, existiendo áreas que pueden verse relativamente a salvo. Esto significa también que no todo el subsistema le va a conceder la misma importancia ni va a reaccionar igual ante su presencia (puede que, por ejemplo, algunos sectores crean que se benefician con él, como cuando la oposición observa satisfecha las crecientes dudas sobre la labor del gobierno, sin percatarse de que en cualquier momento estas mismas dudas también pueden volverse contra ella). 
Como el subsistema no responde ni de inmediato ni masivamente al escepticismo, el incremento del descontrol y las oportunidades de sentido que ponen de manifiesto los errores de conducción, los problemas de interpretación, las ambigüedades, la contingencia, etc., van abriendo nuevos espacios para el procesamiento de la duda.

En este subsistema que se va haciendo crítico, el complejo de los medios de difusión masiva encuentra satisfacción a su imparable demanda de noticias (que captura mediante la interpenetración) mismas que repercuten drásticamente sobre el subsistema (también por interpenetración) porque no han sido elaboradas por él y, en consecuencia, importan sentidos que le resultan incomprensibles.

Pero como no todo el subsistema está subvertido por el escepticismo, la parte que permanece fiel a sus principios, además de que nota los estragos, intenta reducirlo: ignorándolo o minimizándolo ("no es más que un problema sin importancia o un problema pasajero"), derivándolo hacia otros ("no es mi problema"), reprimiéndolo (como lo intentan los regímenes autoritarios), y cuando todo esto falla, buscando formas de conjurarlo (nuevas alianzas entre los sectores políticos, nuevos programas y proyectos políticos, campañas contra la corrupción, etc.).

Pero estas acciones que bastan cuando se trata sólo de dudas aisladas son ineficaces en el campo del escepticismo, porque éste es capaz de poner a tela de juicio los valores mejor protegidos por el subsistema (su legitimidad, la democracia, su capacidad para "gobernar" el sistema social, etc.).

Es decir que el escepticismo, una vez que comienza a subvertir el código del subsistema político, y precisamente a partir del manejo tendencioso que hace de él, altera la credibilidad en todos los niveles (jerarquías, organización, normas de operación, instituciones, etc.).

Por su aparición policentrica, se lo combate en un área y aparece en otra, y no deja de afectar a aquellos mismos que lo combaten porque ocasionalmente retoman parte de su discurso (al menos cuando se refieren a sus enemigos).

Pero el proceso desencadenado no es pura destrucción, ni pura negatividad (en la acepción que A. Schutz le daba a ese término), sino que el escepticismo político crea situaciones nuevas ( $\mathrm{si}$ no se cree ni en el gobierno ni en la oposición, se forman, por ejemplo, movimientos populares para resolver los problemas de una comunidad), abre 
nuevas oportunidades de sentido (mediante preguntas cada vez menos superficiales que permiten aflorar problemas que no estaban claros), ofrece otra perspectiva del sistema social y del sistema político (porque mediante la duda "ve" y enseña a "ver" cuestiones nuevas, cuestiones que ya estaban pero que no se percibían) o compite con las formaciones de sentido sedimentadas por la experiencia y sobrevalorizadas en la selección por el subsistema (muchas de las cuales pueden haber perdido su funcionalidad).

\section{3. ¿Cuándo es posible abandonar el código del escepticismo político?}

Si hubiera alguna fórmula especial para esto no habría escepticismo. Pero, en general, el abandono de la supremacía del código de la improbabilidad-probabilidad sobre el del gobierno-oposición es el resultado de los procesos mismos que han sido desencadenados por ellos (uno en su duda y su búsqueda recurrentes y otro en su autorrefente búsqueda de autoafirmación y desarrollo).

Cuando el escepticismo ha penetrado en un subsistema como el político, no se limita a desvirtuar y convertir en duda toda su capacidad de comunicación, sino que, sujeto a su propia dinámica autorrefente, continúa creando sentido en torno a dudas cada vez más complejas. Esta forma de problematizar enfatiza, por lo general, el término de improbabilidad contenido en el código escéptico, pero a fuerza de ahondar en esta perspectiva, también van quedando al descubierto ciertos márgenes (no todas las cosas son igualmente improbables) que abren sentido a la probabilidad, y desde ella a una confianza provisional. Asimismo, la duda en sí conlleva la búsqueda (ya que si no hubiera dudas, la búsqueda no tendría sentido) y el desarrollo de nuevas dudas a partir del ejercicio de la búsqueda, en cuyo proceso algunas dudas menores quedan resueltas (es decir que también se puede superar la duda desde la duda misma, a ciertos niveles). De modo que la evolución recursiva y autopoiética ${ }^{15}$ de la duda puede conllevar mediante un bucle extraño ${ }^{16}$ a la pérdida de fuerza de la improbabilidad frente a la

\footnotetext{
${ }^{15}$ Autopoiética; autogenerativa mediante la autorreferencia.

${ }^{16}$ Douglas F. Hofstadter denomina bucle extraño al fenómeno que ocurre cada vez que "habiendo hecho hacia arriba (o hacia abajo) un movimiento a través de los niveles de un sistema jerárquico dado, nos
} 
probabilidad y, con ello abrir la posibilidad de que el subsistema político logre reconducir su propio código. De hecho, esto pasa en alguna medida siempre que se presenta el escepticismo político.

Sin embargo, es de la mayor importancia (de más importancia que lo que sucede dentro del juego del escepticismo político al procesar la duda), la reacción que tiene que forjarse dentro del propio subsistema politico para asumir nuevamente su autocontrol (que se logra cuando vuelve a operar su código libre de agentes extraños).

Ahora bien, dentro del subsistema político el escepticismo es percibido como subversión - y desde luego que lo es puesto que trastoca, desde su código hasta las más elementales formas de comunicación que se dan en su seno.

Eso explica que, a medida que el escepticismo se extiende, el sistema político trate primero de eliminarlo de una manera relativamente tosca (censura, represión, ridicularización) y luego con estrategias mucho más elaboradas. En ocasiones el costo de eliminar el escepticismo implica en parte el sacrificio de su propio discurso, lo que suele presentarse en varios países en momentos previos a las selecciones; si el discurso político está agotado por efecto de las dudas que la propia conducción política o que los medios de difusión han provocado, los políticos recurren entonces a un discurso clientelar (así, se ofrecen candidatos a diputados, senadores o presidentes, con más "garantías" que una lavadora, o se conceden votos a cambio de la solución de ciertos problemas como es en México el caso de "Solidaridad").

En otras ocasiones, el sistema debe reasignar sus recursos más importantes para formular acciones más contundentes, mediante programas y proyectos que recuperan la credibilidad perdida (cuyo enorme costo no siempre son capaces de soportar). Pueden lograr así considerables éxitos (como el triunfal discurso de Busch al terminar la Operación Tormenta del Desierto) y también, en ocasiones, pueden perder lo ganado, al

encontramos inopinadamente en el punto de partida" (en Godel, Escher y Bach, La Eterna Trenza Dorada, ed. Conacyt, México, 1982. Esto se puede extrapolar a la situación del procesamiento del escepticismo dentro del subsistema político (que es un sistema jerárquico), cuando dudas de distinto nivel conducen a una certeza. Por ejemplo: la duda de que el gobierno autorice un congelamiento de precios, aunada a la duda de que la política antiinflacionaria que está siguiendo sea adecuada, pueden conducir a la certeza de que las condiciones de vida empeorarán para la clase trabajadora. 
continuar con las prácticas que originaron su descrédito (por ejemplo, la Operación Tormenta del Desierto de Busch fue un éxito que no ha podido disfrutar mayormente, por sus errores en la conducción de los asuntos internos que han hecho que los ciudadanos vuelvan a dudar de la eficacia de su gobierno y en un momento considerablemente más importante para su gestión).

Otros períodos de escepticismo político han dado lugar en cambio a proyectos revolucionarios capaces de reconducir la identidad del subsistema, que se ha visto fortalecida, en tanto el escepticismo a nivel del sistema social casi desapareció.

No existe, por lo tanto, una forma única de salir del juego escéptico para el subsistema político, pero hay varias alternativas que históricamente ya han tenido lugar.

Nuestro modelo queda, así, abierto al sentido que él mismo pueda ir desarrollando. Su confrontación con otro modelo, el desarrollado por J.B.Thompson, seguramente permitirá afinar algunos de sus mecanismos (y también lo hará con el de Thompson).

Por ahora, la indagación está abierta para contrastar resultados.

Ciudad Universitaria, mayo de 1992. 